\title{
Vasorelaxation Effects of 2-Chloroethanol and Chloroacetaldehyde in the Isolated Rat Aortic Rings
}

\author{
Yng-Tay Chen, ${ }^{a}$ Dong-Zong Hung, ${ }^{b}$ Chi-Chung Chou, ${ }^{a}$ Jaw-Jou Kang, ${ }^{c}$ Yu-Wen Cheng, ${ }^{d}$ \\ Chien-Ming Hu, ${ }^{e}$ and Jiunn-Wang Liao*, $f$
}

${ }^{a}$ Department of Veterinary Medicine, National Chung-Hsing University, 250, Kuo-Kuang Road, Taichung 40227, Taiwan, Republic of China, ${ }^{b}$ Toxicology Center, China Medical University Hospital, and Graduate Institute of Drug Safety, China Medical University, 2, Yuh-Der Rd., Taichung 40402, Taiwan, Republic of China ${ }^{c}$ Institute of Toxicology, College of Medicine, National Taiwan University, 1, Jen-Ai Road, Section 1, Taipei 10051, Taiwan, Republic of China, ${ }^{d}$ School of Pharmacy, Taipei Medical University, 250, Wu-Shing Street, Taipei 11031, Taiwan, Republic of China, ${ }^{e}$ Emergency Department, Taipei Medical University Hospital, 252, Wu-Shing Street, Taipei 11031, Taiwan, Republic of China and ${ }^{f}$ Graduate Institute of Veterinary Pathobiology, National Chung-Hsing University, 250, Kuo-Kuang Road, Taichung 40227, Taiwan, Republic of China

(Received February 5, 2009; Accepted April 27, 2009)

\begin{abstract}
2-Chloroethanol (2-CE) is a commonly used solvent in industry; unfortunately, severe hypotension is one of main toxic signs during intoxication. Calcium ion modulation is considered to be an important role of vasorelaxation. The aim of this study is to evaluate either 2-CE or its main metabolite, chloroacetaldehyde (CAA), possible cause of hypotension, by using isolated rat aortic rings. Results revealed that 2-CE caused a weakly relaxation in the phenylephrine (PE) pre-induced endothelium-intact aortic rings. However, its metabolite, CAA induced vasorelaxation and showed dose dependency in endothelium-intact and -denuded aortic rings. The half inhibitory concentration $\left(\mathrm{IC}_{50}\right)$ of 2-CE exceeded $50 \mathrm{mM}$; meanwhile, the $\mathrm{IC}_{50}$ values of CAA in the endothelium-intact and -denuded aortic rings were 3.3 and $2.7 \mathrm{mM}$, respectively. The CAA-induced relaxation could be significantly attenuated by adding calcium $\left(\mathrm{CaCl}_{2}\right)$ and various $\mathrm{Ca}^{2+}$ channel blockers, dantrolene, nifedipine, and $\mathrm{NiCl}_{2}$. $\mathrm{Nifedipine}^{2}$ presents the most strong inhibition effect among the calcium blockers. In conclusion, it is suggested that the hypotension effect of 2-CE intoxicated cases may be mainly mediated by its metabolite CAA, and calcium channels are partially involved inducing the vasorelaxation.
\end{abstract}

Key words — 2-chloroethanol, chloroacetaldehyde, relaxation, calcium channel blocker, rat aorta ring

\section{INTRODUCTION}

2-Chloroethanol (2-CE) (CAS 107-07-3) is commonly applied as a solvent in industry. It is also an intermediate product in the synthesis of various chemical compounds. Acute poisoning cases of 2-CE by ingestion of film cement have been reported. ${ }^{1)}$ In Taiwan, some grape farmers use 2$\mathrm{CE}$ to cultivate grapevines as it hastens sprouting. For this, accidental acute poisonings or fatalities of 2-CE in farmers have been reported. ${ }^{2)}$ In fatal cases of 2-CE, patients show hypotension, metabolic acidosis, coma, respiratory failure and death after acute exposure. ${ }^{2,3)}$ The 2-CE also

\footnotetext{
*To whom correspondence should be addressed: Graduate Institute of Veterinary Pathobiology, National Chung-Hsing University, 250, Kuo-Kuang Road, Taichung, 402 Taiwan, Republic of China. Tel.: +886-4-22840894 (Ext. 406); Fax: +886-422862073; E-mail: jwliao@ dragon.nchu.edu.tw
}

causes neurotoxicity, characterized by lethargy, unresponsiveness to touch and erratic movements that is mediated by its metabolite chloroacetaldehyde (CAA) ${ }^{4)}$ Another possible mechanism of CAA's toxicity in hepatocytes involves protein-thiol depletion, and mitochondrial damage, which causes adenosine triphosphate (ATP) decrease and calcium cycling. ${ }^{5)}$ Additionally, the membrane proteins can actively transport $\mathrm{Ca}^{2+}$ out of the cytosol through the ATP-dependent $\mathrm{Ca}^{2+}$ pumps in the plasma membrane and the sarcoplasmic reticulum (SR). ${ }^{6}$ Based on the structure relationship of CAA, the direct vasorelaxant action of acetaldehyde (AA), one of the metabolites of alcohol, on vascular smooth muscles is believed to play a significant role in the ethanolinduced peripheral vasodilation, hypotension and cardiovascular collapse that occur in the alcoholabuse reaction. ${ }^{7)}$

$\mathrm{Ca}^{2+}$ is well known to be important in regulat- 
ing vascular tone. A rise in free $\mathrm{Ca}^{2+}$ concentration, which is caused by $\mathrm{Ca}^{2+}$ entry through ion channels in the plasma membrane and by the release of $\mathrm{Ca}^{2+}$ from the SR via ryanodine receptors and inositol 1,4,5-trisphosphate $\left(\mathrm{IP}_{3}\right)$ receptors, initiates the contraction of vascular smooth muscle. ${ }^{8)}$ Extracellular $\mathrm{Ca}^{2+}$ enters the intracellular space mostly through voltage-dependent $\mathrm{Ca}^{2+}$ channels (VDCCs) and hormone-mediated receptor-operated $\mathrm{Ca}^{2+}$ channels (ROCCs). ${ }^{9,10)} \mathrm{L}$ type voltage-operated $\mathrm{Ca}^{2+}$ channels (VOCCs) antagonist nifedipine and store-operated $\mathrm{Ca}^{2+}$ channels (SOCCs) antagonist $\mathrm{NiCl}_{2}$ are also found to block calcium channel. ${ }^{11}$ ) We hypothesized that the vascular effect of CAA may involve the mobilization of $\mathrm{Ca}^{2+}$ in the hypotension toxicity. However, the effects of 2-CE, and the metabolite of CAA on hypotension remain unclear. The aim of this study is to examine the vasorelaxation effect of 2-CE and CAA by using the isolated rat aortic rings. Futhermore, relaxation change of calcium ions blockers in the 2-CE and CAA treatments are also examined.

\section{MATERIALS AND METHODS}

Chemicals — 2-CE, CAA, phenylephrine (PE), acetylcholine (ACh), ethylene glycol $\operatorname{bis}(\beta$ aminoethyl ether)- $N, N, N^{\prime}, N^{\prime}$,-tetraacetic acid (EGTA), 2-aminoethyl diphenylborinate (2-APB), dantrolene, nifedipine and $\mathrm{NiCl}_{2}$ were purchased from Sigma Co. (Saunt Louis, MO, U.S.A.).

Animals — Sprague-Dawley rats, male, weighing 250-300 g, were obtained from the BioLASCO Taiwan CO., Ltd. (I-Lan, Taiwan, China). The animals were housed in cages with ample access to food (Lab Diet ${ }^{\circledR} 5001$ Rodent diet, PMI ${ }^{\circledR}$ Nutrition International, LLC, St. Louis, MO, U.S.A.), and were provided with deionized reverse osmosis water ad libitum. The animals were kept at $20-25^{\circ} \mathrm{C}$ and $40-70 \%$ relative humidity under a $12 \mathrm{hr}$ light on/off cycle. The experiment was performed according to the criteria for the use and care of experimental animals, set out in the "A Guidebook for the Care and Use of Laboratory Animals."12)

\section{Preparation and Treatment of Aortic Rings -}

The rat aortic rings were isolated according to the method of den Hartiz et al. ${ }^{13)}$ and our previous method. ${ }^{14)}$ Rats were anesthetized by an intraperitoneal injection of urethane $(0.6 \mathrm{~g} / \mathrm{kg})$ combined with chlorohydrate $(0.4 \mathrm{~g} / \mathrm{kg})$, and blood was exsanguinated from the abdominal aorta. The tho- racic aorta was carefully removed. Fat and tissue were dissected in normal Krebs solution $(\mathrm{NaCl}$ $118.5 \mathrm{mM}, \mathrm{KCl} 4.8 \mathrm{mM}, \mathrm{MgSO}_{4} 1.2 \mathrm{mM}, \mathrm{KH}_{2} \mathrm{PO}_{4}$ $1.2 \mathrm{mM}, \mathrm{NaHCO}_{3} 25 \mathrm{mM}$, glucose $11.1 \mathrm{mM}, \mathrm{CaCl}_{2}$ $2.5 \mathrm{mM}, \mathrm{pH} 7.4)$. The aorta was cut into rings with diameters of approximately $5-8 \mathrm{~mm}$ in a $20 \mathrm{ml}$ organ bath, and constantly gassed with $95 \% \mathrm{O}_{2}$ and $5 \% \mathrm{CO}_{2}$ at $37^{\circ} \mathrm{C}$. Two "L" type stainless steel hooks were then inserted into the aortic lumen, with one fixed to the bottom of the organ bath and the other connected to a force transducer. The aortic rings were equilibrated in Krebs solution and maintained under the optimal tension of $1 \mathrm{~g}$ for $30 \mathrm{~min}$ during which period the Krebs solution was changed three times before the experimental procedures were performed. Aortic ring contraction was recorded, isometrically using a force displacement transducer (Grass SD9 stimulator, Quincy, MA, U.S.A.) that was connected to a PowerLab recorder (ADIntruments, Bella Vista, NSW, Australia). To prepare the denuded aorta rings, the endothelium was removed by rubbing with cotton, and the absence of ACh induced relaxation was regarded as indication of successful denudation. ${ }^{15)}$

Experiment for Effects of 2-CE and CAA in Aortic Rings of Rats — For the relaxation study, aorta rings were pre-contracted using PE $(5 \mu \mathrm{M})$ for $15 \mathrm{~min}$, before 2-CE $(1,3,10,25$ and $50 \mathrm{mM})$ was added to the endothelium-intact aortic rings. Concentrations of $0.1,0.5,1,10 \mathrm{mM}$ CAA was individually incubated in either the endothelium-intact or endothelium-denuded aortic rings for $60 \mathrm{~min}$. The percentages of PE-induced relaxation of 2-CE and CAA were calculated after incubation.

Experiment for Effects of CAA-induced Relaxation with/without Calcium — Endotheliumdenuded aortic rings were incubated with either Krebs solution or a $\mathrm{Ca}^{2+}$-free (which contained $50 \mu \mathrm{M}$ EGTA) modified Krebs solution, and were pre-contracted using PE $(5 \mu \mathrm{M})$. Subsequently, CAA $(3 \mathrm{mM})$ was added for $10 \mathrm{~min}$ before $\mathrm{CaCl}_{2}$ $(5 \mathrm{mM})$ was added last. The CAA relaxation of aortic rings was measured for $60 \mathrm{~min}$ and $\mathrm{PE}$-induced was expressed as a percentage of the PE-induced maximal contraction. ${ }^{16,17)}$

Experiment for $\mathrm{Ca}^{2+}$ Channel Blockers in CAA Relaxed Aortic Ring of Rats — The aortic rings of the rats were pre-incubated with various $\mathrm{Ca}^{2+}$ channel blockers: 2-APB (an $\mathrm{IP}_{3}$ receptor blocker, $75 \mu \mathrm{M}$ ), dantrolene (a ryanodine receptor blocker, $50 \mu \mathrm{M}$ ), nifedipine (a L-type blocker, $1 \mu \mathrm{M}$ ) and $\mathrm{NiCl}_{2}$ (non-selective $\mathrm{Ca}^{2+}$ channel blocker, $1 \mathrm{mM}$ ), 
in standard Krebs solution, or $\mathrm{Ca}^{2+}$ free EGTA Krebs solution for $30 \mathrm{~min}$. The resting tension of endothelium-intact aortic rings was initially set at $3 \mathrm{~g}$. Then, the aortic rings were treated with PE $(5 \mu \mathrm{M})$ for $15 \mathrm{~min}$ to induce contraction. Finally, CAA $(3.0 \mathrm{mM})$ was added into the organ bath, and the remaining tension of the rings was measured for $60 \mathrm{~min}$.

In order to evaluate the calcium channels blocker role of CAA. Aortic rings were incubated with CAA $(3 \mathrm{mM})$ for $30 \mathrm{~min}$. The resting tension of the endothelium-intact and endothelium-denuded aortic rings was initially set to $3 \mathrm{~g}$. The aortic rings were pre-contracted using PE $(5 \mu \mathrm{M})$, and then incubated with $\mathrm{Ca}^{2+}$ channel blockers 2-APB $(75 \mu \mathrm{M})$ or nifedipine $(1 \mu \mathrm{M})$. The final contraction responses to $\mathrm{PE}$ in the aortic rings were measured after $60 \mathrm{~min}$. The relaxation tensions were measured following an initial tension of $3 \mathrm{~g}$ and a PE pre-constructed initial tension, and compared with 2-APB and nifedipine caused relaxation.

Statistical Analysis — The half inhibitory concentration $\left(\mathrm{IC}_{50}\right)$ was calculated using Excel, MicroSoft. Data are expressed as mean \pm standard deviation. Statistical differences were evaluated by the Student $t$-test. Differences were regarded as significant at $p<0.05$.

\section{RESULTS AND DISCUSSION}

\section{2-CE and CAA Relaxed Aortic Rings}

Rat aortic rings pre-contracted with $\mathrm{PE}(5 \mu \mathrm{M})$ for $15 \mathrm{~min}$, following by ACh $(3 \mu \mathrm{M})$ treatment for verification of the function of the vascular endothelium. As shown in Fig. 1, the endothelium-intact function of aortic ring were verified by the relaxation rate of more than $60 \%$ (our result of undamaged endothelium relaxed was $74.8 \pm 13.2 \%$ ), while the endothelium-denuded was confirmed by the inability of aortic rings to relax in response to ACh. ${ }^{15)}$ In this study, 2-CE caused a weakly relaxation in the PE pre-induced endothelium-intact aortic rings. However, its metabolite, CAAinduced vasorelaxation in a dose dependent manner in both endothelium-in tact and -denuded aortic rings (Fig. 2). The 2-CE and CAA affected vasorelaxation are shown in Table 1 . The $\mathrm{IC}_{50}$ of 2-CE in endothelium-intact aortic ring relaxation is higher than $50 \mathrm{mM}$. The $\mathrm{IC}_{50}$ values of CAA-induced relaxations in the endothelium-intact and endothelium-denuded aortic rings are 3.3 and

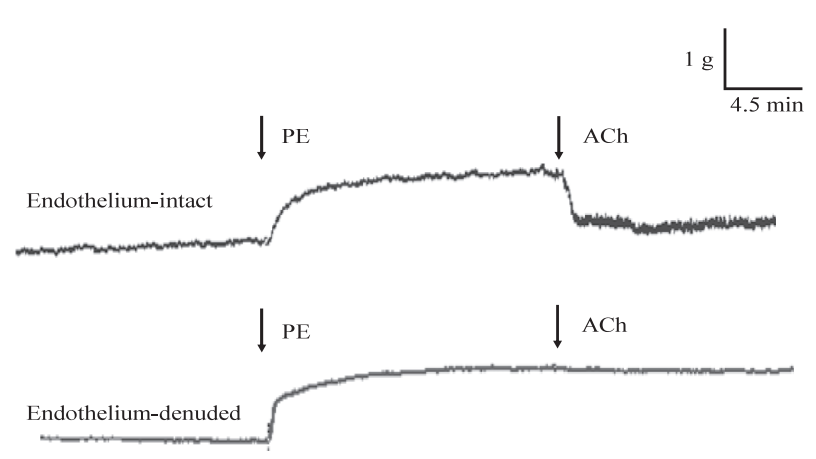

Fig. 1. Vasorelaxation Effect of PE Induced Contraction in Endothelium-intact and -denuded Rat Aortas

Aorta rings were precontracted with $\mathrm{PE}(5 \mu \mathrm{M})$ for $15 \mathrm{~min}$ and treated with $\mathrm{ACh}(3 \mu \mathrm{M})$ served as positive control.

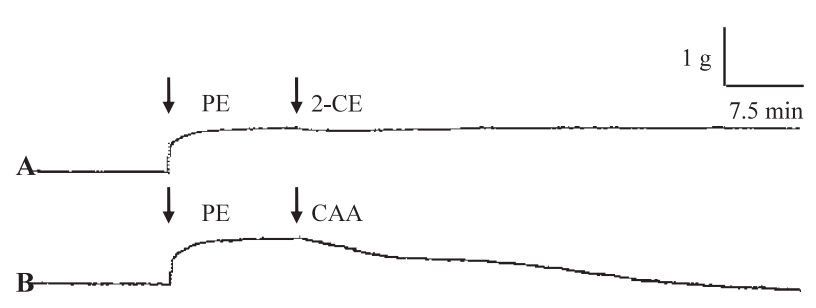

Fig. 2. Effects of 2-CE and CAA in the Isolated Rat Aortic Rings

Chart-photograph of $10 \mathrm{mM}$ 2-CE and $10 \mathrm{mM}$ CAA incuded relaxation in endothelium-intact aortic rings were recorded for $60 \mathrm{~min}$ after pre-contracting with PE $(5 \mu \mathrm{M})$ for $15 \mathrm{~min}$.

$2.7 \mathrm{mM}$, respectively. In the clinics, 2-CE intoxicated patients commonly presented with marked hypotension. ${ }^{2)}$ One of the known 2-CE metabolites in liver $^{4)}$ and in blood ${ }^{18)}$ is CAA. It was also known that high doses of ifosfamide (IF) and cyclophosphamide $(\mathrm{CP})$ are associated with severe but generally reversible cardiotoxicity in human. One of their metabolite CAA is commonly evoked to explain the adverse effects of both IF and CP. ${ }^{19-21)}$ A previous study has shown that $0.02 \mathrm{ml} / \mathrm{kg}$ CAA could cause hypotension, respiration failure and always accompanies neuromuscular contraction in rabbits. ${ }^{22)}$ The toxic effect of 2-CE leading to hypotension could be ascribed to its metabolite of CAA action in our finding.

\section{$\mathrm{CaCl}_{2}$ Attenuation on CAA Relaxed Aortic Rings}

In a $\mathrm{Ca}^{2+}$-free condition, the CAA-induced relaxation effect showed no difference between endothelium-intact and endothelium-denuded aortic rings. The tensions of CAA-induced relaxation in the endothelium-denuded aortic rings' tension rate were $61.7 \%$ of the control (Fig. 3). Addi- 
Table 1. Relaxation Effects of 2-Chloroethanol and Chloroacetaldehyde in the Isolated Rat Aortic Rings

\begin{tabular}{cccc}
\hline \hline Chemical & $\begin{array}{c}\text { Concentration } \\
(\mathrm{mM})\end{array}$ & \multicolumn{2}{c}{$\begin{array}{c}\text { Relaxation } \\
(\% \text { of PE pre-contracted })^{a)}\end{array}$} \\
\cline { 2 - 4 } & & $\begin{array}{c}\text { Intact aortic } \\
\text { ring }\end{array}$ & $\begin{array}{c}\text { Denuded aortic } \\
\text { ring }\end{array}$ \\
\hline 2 -CE & 1 & $0.6 \pm 1.0$ & - \\
& 3 & $9.0 \pm 4.2^{*}$ & - \\
& 10 & $11.5 \pm 4.0^{*}$ & - \\
& 25 & $27.0 \pm 5.5^{*}$ & - \\
& 50 & $34.5 \pm 1.1^{*}$ & - \\
CAA & 0.05 & $0.5 \pm 0.8$ & - \\
& 0.1 & $11.5 \pm 3.5^{*}$ & 0 \\
& 0.5 & $47.4 \pm 8.1^{*}$ & $25.1 \pm 8.6^{*}$ \\
& 1 & $52.9 \pm 0.3^{* \#}$ & $44.8 \pm 6.2^{*}$ \\
& 10 & $100.0^{*}$ & $100.0^{*}$ \\
\hline CAA & $\mathrm{IC}_{50}(\mathrm{mM})$ & 3.3 & 2.7 \\
\hline
\end{tabular}

-: not done. $a$ ): The percentage of relaxation of PE-induced contraction by 2-CE or CAA were calculated at the end of 60 min incubation. Data are expressed as mean \pm S.D. $(n=3-4) .{ }^{*} p<0.05$ vs. control, ${ }^{\#} p<0.05$ vs. 2-CE.

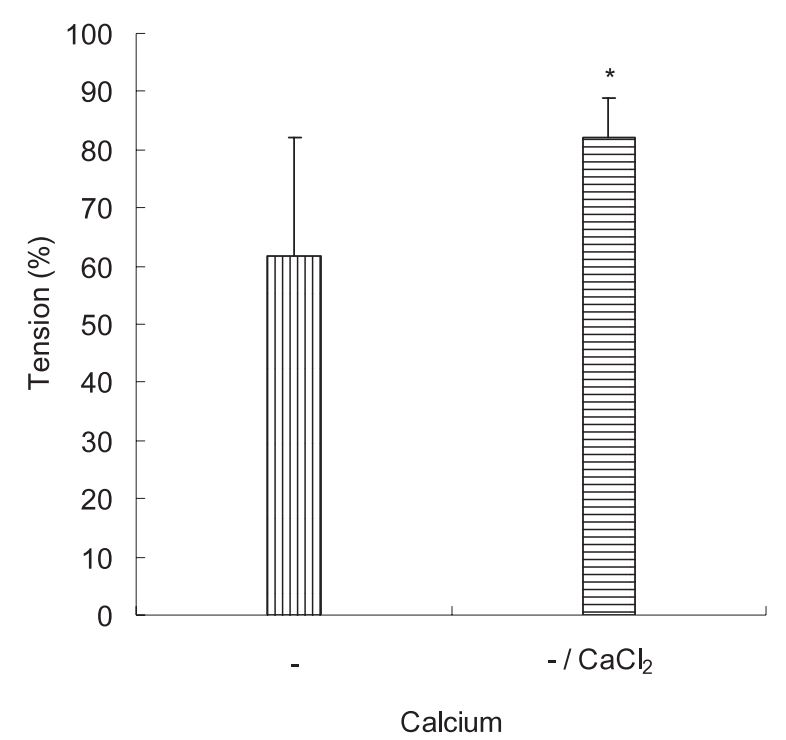

Fig. 3. Effects of Calcium on CAA-induced Relaxation in the Endothelium-denuded Rat Aortic Rings

Incubation of CAA either with or without $\mathrm{Ca}^{2+}$ solution was followed by provision of $\mathrm{CaCl}_{2}$ that reduced relaxation in the endothelium-denuded aorta rings. Relaxation (\%) of PE-induced contraction by CAA was recorded at the end of $60 \mathrm{~min}$ incubation. Data are expressed as mean \pm S.D. $(n=4)^{*} p<0.05 v$ s. calcium free group.

tion of $\mathrm{CaCl}_{2}$ to the $\mathrm{Ca}^{2+}$-free condition after $\mathrm{CAA}$ could significantly reverse the inhibited tension rate $(82.4 \%)$ in the endothelium-denuded aortic rings $\left({ }^{*} p<0.05\right.$, Fig. 3$)$. It is suggetsted that the $\mathrm{Ca}^{2+}$ ion acts as a trigger of contraction in vascular smooth muscles. ${ }^{8)}$ Calcium ion influxes intracellular through the plasma membrane, and refluxes from SR to cause vascular contraction..$^{9,23,24)}$ Our results

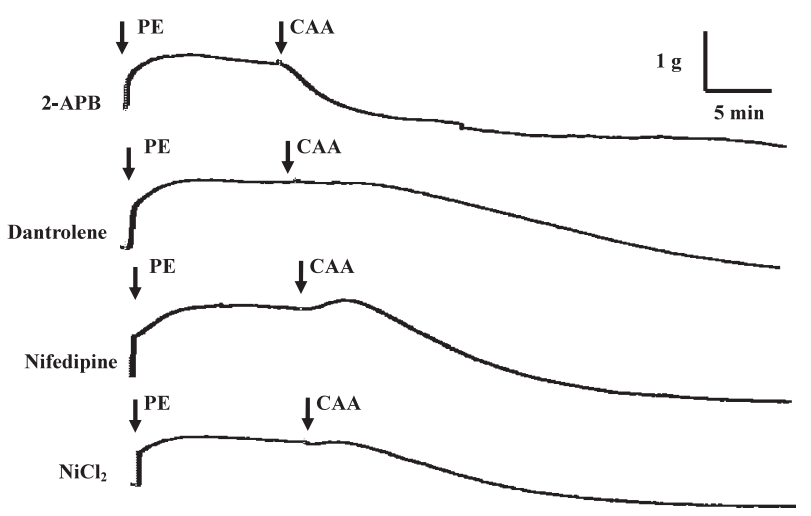

Fig. 4. Chart-photographs of Calcium and Calcium Channel Blockers on CAA-induced Relaxation of Endotheliumintact Rat Aortic Rings

Aortic rings were pre-incubated with various calcium channel blockers, 2-APB $(75 \mu \mathrm{M})$, dantrolene $(50 \mu \mathrm{M})$, nifedipine $(1 \mu \mathrm{M})$ and $\mathrm{NiCl}_{2}(1 \mathrm{mM})$ for $30 \mathrm{~min}$ before CAA was added to relaxe PE $(5 \mu \mathrm{M})$ pre-contracted rat aortic rings for $60 \mathrm{~min}$.

showed that CAA-induced vasorelaxation in the rat aortic rings might involve calcium mobilization in smooth muscle cells.

\section{$\mathrm{Ca}^{2+}$ Channel Blockers Reduce CAA-induced Vasorelaxation}

Chart-photographs of CAA-induced vasorelaxation of aortic rings after pre-incubation with various $\mathrm{Ca}^{2+}$ channel blockers are shown in Fig. 4. The levels of remained tensions rate $(\%)$ in the aortic rings pre-incubated with 2 -APB was $73.3 \%$, and $81.4 \%$ in $\mathrm{Ca}^{2+}$-free media (Fig. 5). Calcium channel 


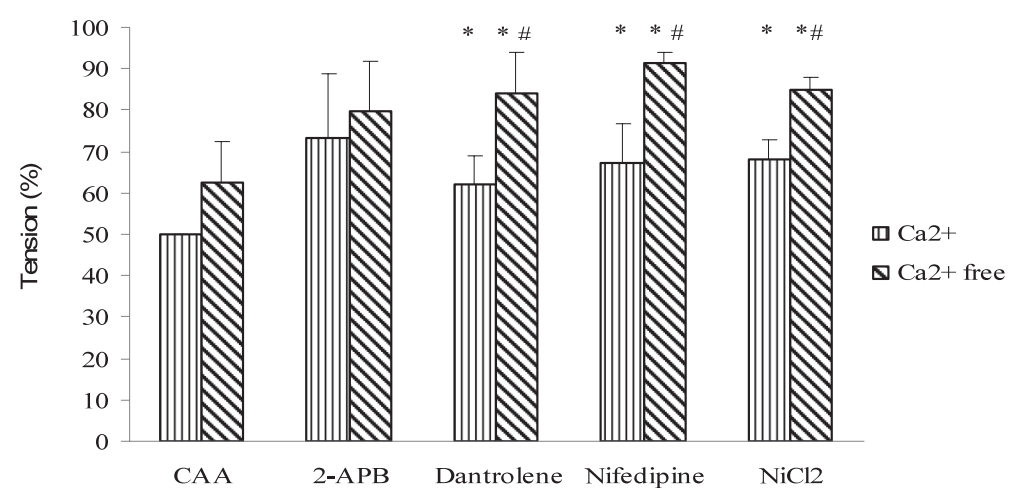

Fig. 5. Inhibited Effects of Calcium Channel Blockers on CAA-induced Relaxation of Endothelium-intact Rat Aortic Rings Aortic rings were pre-incubated with various calcium channel blockers, 2-APB $(75 \mu \mathrm{M})$, dantrolene $(50 \mu \mathrm{M})$, nifedipine $(1 \mu \mathrm{M})$ and $\mathrm{NiCl}_{2}(1 \mathrm{mM})$ for $30 \mathrm{~min}$, and then pre-contracted with PE $(5 \mu \mathrm{M})$, then treated with CAA $(3 \mathrm{mM})$ for $60 \mathrm{~min}$. Data are expressed as- mean \pm S.D. $(n=4-6){ }^{*} p<0.05$ vs. control, ${ }^{\#} p<0.05$ calcium free group $v s$. normal Krebs solution group.

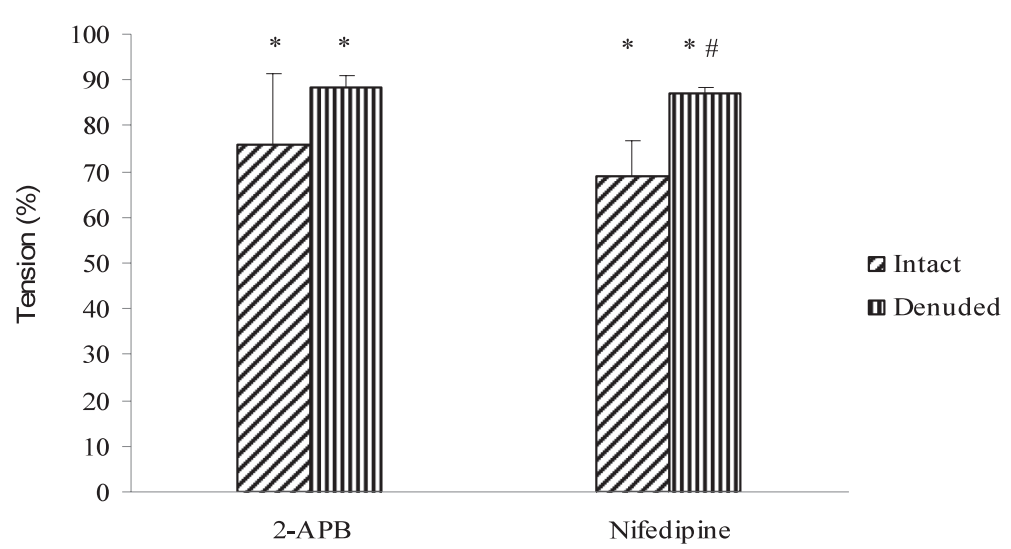

Fig. 6. Inhibited Effects of CAA on Calcium Channel Blockers-induced Relaxation in the Functional Endothelium Aortic Rings CAA were pre-incubated on endothelium-intact and -denuded aortic rings for $30 \mathrm{~min}$, and then pre-contracted with PE $(5 \mu \mathrm{M})$, then treated with 2-APB $(75 \mu \mathrm{M})$ or nifedipine $(1 \mu \mathrm{M})$ for $60 \mathrm{~min}$. Data are expressed as mean \pm S.D. $(n=4-6){ }^{*} p<0.05 v s$. control, ${ }^{\#} p<0.05$ denuded $v s$. intact group.

blocker 2-APB is known to inhibit the $\mathrm{IP}_{3}$-induced release of $\mathrm{Ca}^{2+}$ from mouse cerebellar membrane in a concentration-dependent manner without affecting $\mathrm{IP}_{3}$ binding. ${ }^{25)}$ In this study, aortic rings were pre-incubated with 2-APB, and the vasorelaxation caused by CAA were not significantly affected, either in Krebs solution or $\mathrm{Ca}^{2+}$-free conditions. Tirapelli ${ }^{26)}$ has found that $\mathrm{IP}_{3}$ causes intracellular $\mathrm{Ca}^{2+}$ release after PE treatment, which does not contribute to the response of alcohol-treated aortic rings. These may undergo $\mathrm{PE}$ binding to the $\mathrm{IP}_{3}$ receptor channel and release $\mathrm{Ca}^{2+}$ from $\mathrm{SR}$ and cause the aortic rings to contract. ${ }^{27)}$ These reasons might explain why PE does not cause contraction after 2-APB incubation under $\mathrm{Ca}^{2+}$-free conditions.

$\mathrm{Ca}^{2+}$ channels open in the SR membrane via $\mathrm{IP}_{3}$ receptors and ryanodine receptors. ${ }^{9,}{ }^{10)}$ Dantrolene is an agent that inhibits the release of intra- cellular $\mathrm{Ca}^{2+}$ via ryanodine receptors. ${ }^{24)}$ The tension of dantrolene treatment was $62.1 \%\left({ }^{*} p<0.05\right.$ vs. CAA alone), and $83.9 \%$ in $\mathrm{Ca}^{2+}$-free conditions $\left({ }^{*} p<0.05 v s . \mathrm{CAA},{ }^{\#} p<0.05 v s\right.$. Krebs normal solutions, Fig. 5). Our results indicated that CAAinduced vasorelaxation might be involved in the inhibition of $\mathrm{Ca}^{2+}$ release from intracellular stores via ryanodine receptors, and possibly inhibit $\mathrm{Ca}^{2+}$ influx. On the other hand, the tension of nifedipine was $67.4 \%\left({ }^{*} p<0.05 v s\right.$. CAA alone), and $91.5 \%$ in $\mathrm{Ca}^{2+}$-free conditions $\left(^{*} p<0.05 v s\right.$. CAA, ${ }^{\#} p<0.05 v s$. Krebs normal solutions, Fig. 5), the $\mathrm{Ca}^{2+}$ channel blocker nifedipine had most effective inhibition of the CAA-induced relaxation, especially in a $\mathrm{Ca}^{2+}$-free medium. L-type plasma membrane $\mathrm{Ca}^{2+}$ release channel in the SR is a response to a change in the electric potential across the plasma membrane. . $^{\text {) }}$ 
In smooth muscle, other L-type $\mathrm{Ca}^{2+}$ channels participate in the extracellular $\mathrm{Ca}^{2+}$ cycle by controlling the $\mathrm{Ca}^{2+}$ that binds to and directly activates the contractile apparatus. ${ }^{11)}$ The results obtained using L-type VOCCs antagonist, nifedipine significantly reduced the relaxation of aortic rings induced by CAA, both in Krebs solution and under $\mathrm{Ca}^{2+}$ free conditions. The tension of the SOCCs antagonist, $\mathrm{NiCl}_{2}$ was $68.3 \%\left(^{*} p<0.05 v s\right.$. CAA alone), and $84.9 \%$ in $\mathrm{Ca}^{2+}$-free conditions $\left({ }^{*} p<0.05 v s\right.$. CAA, ${ }^{\#} p<0.05 v s$. Krebs normal solutions). These results showed that CAA-induced relaxation may involve the inhibition of the release of $\mathrm{Ca}^{2+}$ from a plasma membrane. ${ }^{6)}$

On the other hand, aortic rings were preincubated with CAA and then provided with 2APB or nifedipine. Results showed that 2-APB tension caused in the endothelium-intact and the endothelium-denuded aortic rings was 76.0 and $88.3 \%$, respectively $\left({ }^{*} p<0.05, v s\right.$. CAA alone, Fig. 6). The effect of nifedipine was 69.1 and $86.9 \%$, respectively $\left({ }^{*} p<0.05\right.$, vs. CAA alone, ${ }^{\#} p<0.05$ vs. endothelium-intact, Fig. 6). These findings suggested that CAA-induced vasorelaxation was related to the inhibition of $\mathrm{SR} \mathrm{Ca}^{2+}$ channels in smooth muscle. The antagonistic effect of CAA on the release of intracellular $\mathrm{Ca}^{2+}$ channel in smooth muscle might be related to hypotension due to 2-CE intoxication.

Nitric oxide (NO) is found to stimulate the uptake of cytosolic $\mathrm{Ca}^{2+}$ via the SR $\mathrm{Ca}^{2+}$ ATPase, therefore relaxing vascular smooth muscle by lowering intracellular free $\mathrm{Ca}^{2+}$. NO reacts with superoxide to form peroxynitrite, which in turn caused glutathione to bind to SR $\mathrm{Ca}^{2+}$ ATPase cysteine thiols. ${ }^{28)}$ Chloroacetaldehyde-causesd vasorelaxation might cause the lowing of the concentration of intracellular free $\mathrm{Ca}^{2+}$ and provides one of the reasons for 2-CE caused hypotension in patients. However, the possible roles of NO involvement in CAA-caused vasorelaxation are still unclear.

In summary, 2-CE itself caused weak relaxation in the rat aortic rings. However, its metabolite, CAA, induced significant relaxation both in endothelium-intact and -denuded aortic rings. The CAA caused vasorelaxation might be related to acute intoxication of 2-CE, and the calcium channels might be involved in the initiation of CAA-induced vasorelaxation. However, the underlying mechanisms of the $\mathrm{Ca}^{2+}$ exchange remain unclear and warrant further study.

\section{REFERENCES}

1) Kvistad, P. H., Bolle, R. and Wickstrom, E. (1983) Acute poisoning by ethylene chlorohydrin. Intoxication by ingestion of film cement in two children. Hum. Toxicol., 2, 311-313.

2) Deng, J. F., Yang, C. C., Tsai, W. J., Ger, J. and Wu, M. L. (2001) Acute ethylene chlorohydrine poisoning: experience of a poison control center. J. Toxicol. Clin. Toxicol., 39, 587-593.

3) Mackison, F. W., Stricoff, R. S. and Partridge, L. J. (1980) NIOSH/OSHA Pocket Guide to Chemical Hazards, DHEW (NIOSH), Government Printing Office, Washington, DC, U.S.A.

4) Sood, C. and O'Brien, P. J. (1996) 2-Cloroacetaldehyde-induced cerebral glutathione depletion and neurotoxicity. Br. J. Cancer, 27, S287-S293.

5) Sood, C. and O'Brien, P. J. (1993) Molecular mechanisms of chloroacetaldehyde-induced cytotoxicity in isolated rat hepatocytes. Biochem. Pharmacol., 46, 1621-1626.

6) Katz, A. M. (1996) Calcium channel diversity in the cardiovascular system. J. Am. Coll. Cardiol., 28, 522-529.

7) Altura, B. M., Carella, A. and Altura, B. T. (1978) Acetaldehyde on vascular smooth muscle: possible role in vasodilator action of ethanol. Eur. J. Pharmacol., 52, 73-83.

8) Janowski, E., Cleemann, L., Sasse, P. and Morad, M. (2006) Diversity of $\mathrm{Ca}^{2+}$ signaling in developing cardiac cells. Ann. N. Y. Acad. Sci., 1080, 154-164.

9) Adams, D. J., Barakeh, J., Laskey, R. and Van Breemen, C. (1989) Ion channels and regulation of intracellular calcium in vascular endothelial cells. FASEB J., 3, 2389-2400.

10) Kanneganti, M. and Halpern, N. A. (1996) Acute hypertension and calcium-channel blockers. New Horiz., 4, 19-25.

11) Wang, J., Shimoda, L. A., Weigand, L., Wang, W., Sun, D. and Sylvester, J. T. (2005) Acute hypoxia increase intracellular $\left[\mathrm{Ca}^{2+}\right]$ in pulmonary arterial smooth muscle by enhancing capacitative $\mathrm{Ca}^{2+}$ entry. Am. J. Physiol. Lung Cell. Mol. Physiol., 288, 1059-1069.

12) Yu, J. Y. L., Cheng, C. K., Chen, B. J., Cheng, M. J., Chang, W. J., Chen, H. H. C., Hong, C. C., Lee, P. J., Liang, S. C., Sheu, K. S., Sung, Y. Y., Tang, S. H., Tsai, C. W., Wang, C. S., Wang, M. H., Yen, L. S. and Yu, C. K. (2005) A Guideline for the Care and Use of Laboratory Animals, 3rd Edition, Published by the Chinese Society for the Laboratory Animal Science, Taipei, Taiwan, R.O.C. (in Chinese).

13) den Hartog, G. J., Boots, A. W., Haenen, G. R., van 
der Vijgh, W. J. and Bast, A. (2003) Lack of inhibition of endothelial nitric oxide syntheses in the isolated rat aorta by doxorubicin. Toxicol. In Vitro, 17, 165-167.

14) Hu, C. M., Kang, J. J., Lee, C. C., Li, C. H., Liao, J. W. and Cheng, Y. W. (2003) Induction of vasorelaxation through activation of nitric oxide synthase in endothelial cells by brazilin. Eur. J. Pharmacol., 468, 37-45.

15) Meng, X. H., Ni, C., Zhu, L., Shen, Y. L., Wang, L. L. and Chen, Y. Y. (2009) Puerarin protects against high glucose-induced acute vascular dysfunction: Role of heme oxygenase- 1 in rat thoracic aorta. Vascul. Pharmacol., 50, 110-115.

16) Jiang, H. D., Cai, J., Xu, J. H., Zhou, X. M. and Xia, Q. (2005) Endothelium-dependent and direct relaxation induced by ethyl acetate extract from Flos Chrysanthemi in rat thoracic aorta. J. Ethnopharmaco., 101, 221-226.

17) Qian, L. B., Wang, H. P., Qiu, W. L., Huang, H., Bruce, I. C. and Xia, Q. (2006) Interleukin-2 protects against endothelial dysfunction induced by high glucose levels in rats. Vascul. Pharmacol., 45, 374-382.

18) Dubourg, L., Michoudet, C., Cochat, P. and Baverel, G. (2001) Human kidney tubules detoxify chloroacetaldehyde, a presumed nephrotoxic metabolite of ifosfamide. J. Am. Soc. Nephrol., 12, 1615-1623.

19) Moore, M. J. (1991) Clinicalpharmacokinetics of cyclophosphamide. Clin. Pharmacokinet., 20, 194208.

20) Sladek, N. E. (1994) Metabolism and pharmacokinetic behavior of cyclophosphamide and related oxazaphosphorines. In Anticancer Drugs: Reactive metabolism and drug interaction (Powis, G., Ed.), Pergamon Press, Oxford, pp. 79-156.

21) Wanger, T. (1994) Ifosfamide clinical pharmacokinetics. Clin. Pharmacokinet., 26, 439-456.

22) Lawrence, W. H., Dillingham, E. O., Turner, J. E. and Autian, J. (1972) Toxicity profile of chloroacetaldehyde. J. Pharm. Sci., 61, 19-25.

23) Wray, S., Burdyga, T. and Noble, K. (2005) Calcium signalling in smooth muscle. Cell Calcium, 38, 397407.

24) Ru, X. C., Qian, L. B., Gao, Q., Li, Y. F., Bruce, I. C. and Xia, Q. (2008) Alcohol induces relaxation of rat thoracic aorta and mesenteric arterial bed. Alcohol Alcohol., 43, 537-543.

25) Maruyama, T., Kanaji, T., Nakade, S., Kanno, T. and Mikoshiba, K. (1997) 2APB, 2-aminoethoxyduphenyl borate, a membrane-penetrable modulator of Ins $(1,4,5)$ P-3-induced $\mathrm{Ca}^{2+}$ release. The Journal of Biochemistry, 122, 498-505.

26) Tirapelli, C. R., Al-Khoury, J., Bkaily, G., D’Orléans-Juste, P., Lanchote, V. L., Uyemura, S. A. and de Oliveira, A. M. (2006) Chronic ethanol consumption enhances phenylephrine- induced contraction in the isolated rat aorta. J. Pharmacol. Exp. Ther, 316, 233-241.

27) Ehrlich, B. E. and Watras, J. (1988) Inositol 1,4,5trisphosphate activates a channel from smooth muscle sarcoplasmic reticulum. Nature, 336, 583-586.

28) Cohen, R. A. and Adachi, T. (2006) Nitric-oxideinduced vasodilatation: regulation by physiologic sglutathiolation and pathologic oxidation of the sarcoplasmic endoplasmic reticulum calcium ATPase. Trends Cardiovasc. Med., 16, 109-114. 